\title{
Adaptive Current Control with PI-Fuzzy Compound Controller for Shunt Active Power Filter
}

\author{
Juntao Fei, Kaiqi Ma, Shenglei Zhang, Weifeng Yan, and Zhuli Yuan \\ Jiangsu Key Laboratory of Power Transmission and Distribution Equipment Technology, College of Computer and Information, \\ Hohai University, Changzhou 213022, China
}

Correspondence should be addressed to Juntao Fei; jtfei@yahoo.com

Received 17 September 2012; Revised 30 December 2012; Accepted 31 December 2012

Academic Editor: Jun-Juh Yan

Copyright (C) 2013 Juntao Fei et al. This is an open access article distributed under the Creative Commons Attribution License, which permits unrestricted use, distribution, and reproduction in any medium, provided the original work is properly cited.

\begin{abstract}
An adaptive control technology and PI-fuzzy compound control technology are proposed to control an active power filter (APF). AC side current compensation and DC capacitor voltage tracking control strategy are discussed and analyzed. Model reference adaptive controller for the AC side current compensation is derived and established based on Lyapunov stability theory; proportional and integral (PI) fuzzy compound controller is designed for the DC side capacitor voltage control. The adaptive current controller based on PI-fuzzy compound system is compared with the conventional PI controller for active power filter. Simulation results demonstrate the feasibility and satisfactory performance of the proposed control strategies. It is shown that the proposed control method has an excellent dynamic performance such as small current tracking error, reduced total harmonic distortion (THD), and strong robustness in the presence of parameters variation and nonlinear load.
\end{abstract}

\section{Introduction}

With the development of power electronics technology, nonlinear loads in power system are increasing which generate reactive current and harmonics. Harmonic has some impacts on the safe operation of a variety of electrical equipments and can cause severe damage to the equipment and power system. Active power filter can play role on changing frequency and amplitude of harmonic and reactive current compensation it is an important trend in both harmonic suppression and the current research focus in the field of power electronics technology.

In recent years, shunt active power filter (SAPF) is an effective device to implement the harmonic current in the grid and attracts more and more attention in the modern society; research studies on the APF including harmonic detection, topology studies, system modeling, and control methods become promising topics; the new type of intelligent control and adaptive control methods get a lot of development. There are many current tracking control methods, such as single cycle control, hysteresis current control, space vector control, sliding mode control, deadbeat control, repetitive control, predictive control, fuzzy control, adaptive control, iterative learning control and artificial neural network control. Rahmani et al. [1] introduced a comparative study of shunt hybrid and shunt active power filters for singlephase applications both in simulation and experimental validations. Rahmani et al. [2] implemented an experimental design of a nonlinear control technique for three-phase shunt active power filter. Wang and Luo [3] carried on the quantitative simulation analysis of dead time in fundamental component and harmonic domain. Vahedi et al. [4] reviewed and simulated fixed and adaptive hysteresis current control considering switching losses and high-frequency harmonics. Singh et al. [5] reviewed active power filters for power quality improvement. Singh et al. [6] proposed a new control approach to three-phase active power filter for harmonics and reactive power compensation. Komucugil and Kukrer [7] presented a new control strategy for single-phase shunt APF using a Lyapunov function. Kumar and Mahajan [8] summarized soft computing techniques for the control of an APF. Chang and Shee [9] proposed novel reference 


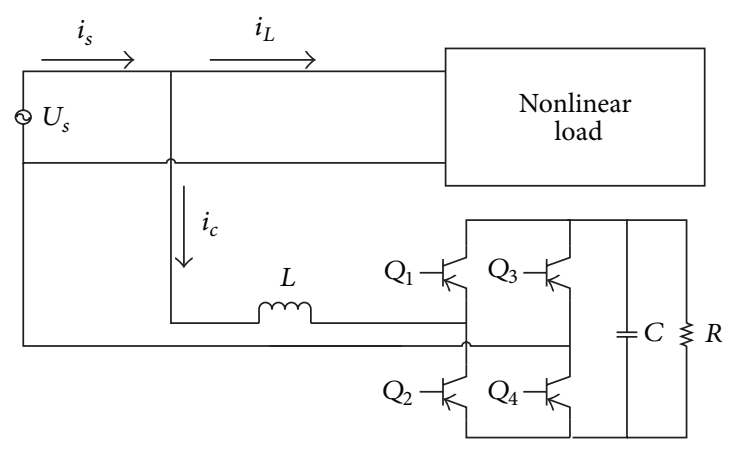

FIgURE 1: Basic circuit structure of shunt APF.

compensation current strategy for shunt APF control. Shyu et al. [10] proposed a model reference adaptive controller to control the circuit, improve the current, and reduce the current harmonics by using the approximate dynamic model of single-phase shunt APF. Matas et al. [11] showed a feedback linearization approach of a single-phase APF via sliding mode control. Hua et al. [12] gave control analysis of an APF using Lyapunov analysis. Montero et al. [13] compared different control strategies for shunt APF in three-phase four-wire systems. Valdez et al. [14] designed an adaptive controller for shunt active filter in the presence of a dynamic load and the line impedance. Marconi et al. [15] developed robust nonlinear controller to compensate harmonic current for shunt active filters. Sriram et al. [16] proposed indirect current control of a single-phase voltage-sourced boost-type bridge converter operated in the rectifier mode. Some other control methods and harmonic suppression approaches for APF have been investigated [17-19]. Singh et al. [20] presented a simple fuzzy logic based robust APF for harmonics minimization under random load variation. Bhende et al. [21] developed a TS-fuzzy controller for load compensation of APF.

However, most of the tracking issues for active power filter's DC voltage or AC current compensation are unilaterally controlled study which cannot achieve accurate, rapid and highly adaptable global control objectives. In this paper, fuzzy logic controller will be investigated to APF since it is very hard to establish accurate mathematical model for APF, classical linear controller cannot achieve the ideal DC voltage tracking performance, and adaptive current tracking control method for AC side current is developed for the current tracking. The proposed adaptive current control method based on PI-fuzzy compound controller for shunt power active filter not only can take advantage of the fuzzy control which does not depend on the system dynamics and has good transient, steady-state behavior, and great robust performance, but also the adaptive control which has precise tracking performance, online real-time compensation of model uncertainties, and external disturbances. Therefore the proposed adaptive current control method based on PI-fuzzy compound controller can greatly improve the current tracking and voltage control performance of the active filter compensation. The proposed control strategy has the following advantages.
(1) This paper integrates the advantages of adaptive control and fuzzy control and applies them to the active power filter. A PI-fuzzy controller is proposed to improve the voltage tracking performance for the DC side capacitor voltage control. A model reference adaptive controller for the AC side current compensation is derived based on Lyapunov analysis.

(2) The proposed adaptive current control method based on PI-fuzzy compound controller can deal with system nonlinearities and nonlinear load better and improve the current tracking and robustness of the control system compared with conventional control method. Fuzzy control has great ability to compensate for the nonlinear load and improve current tracking and total harmonic distortion (THD) performance.

\section{Dynamic Model of Active Power Filter}

This paper studies parallel single-phase voltage active power filter, and the dynamic model of APF is described referring to the linearization model [9]. The circuit diagram is shown in Figure 1.

The APF shown in Figure 1 can be decomposed into two work modes, shown in Figure 2. Assuming the switching converter frequency is $f_{S}$, conversion cycle is $T_{S}=1 / f_{S}$, and duty cycle is $D=T_{\mathrm{ON}} / T_{S}$. In mode (1), when $0<t<D T_{S}, Q_{2}$ and $Q_{3}$ are turned on, $Q_{1}$ and $Q_{4}$ are turned off. In mode (2), when $D T_{s}<t<T_{S}$, conversion process is as opposite mode $1, Q_{2}$ and $Q_{3}$ are turned off, and $Q_{1}$ and $Q_{4}$ are turned on.

According to Figure 2, we can establish the dynamic model of the single-phase shunt active filter as follows:

$$
\begin{aligned}
& \dot{U}_{c}(t)=-\frac{i_{L}-i_{2}}{C} \\
& \dot{i}_{L}(t)=\frac{U_{s}+U_{c}}{L} \\
& \dot{U}_{c}(t)=-\frac{i_{L}-i_{2}}{C} \\
& \dot{i}_{L}(t)=\frac{U_{s}+U_{c}}{L}
\end{aligned}
$$




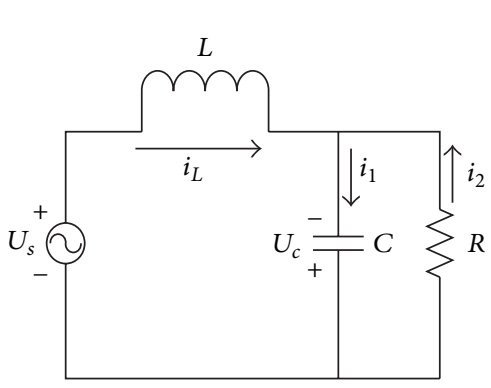

(a)

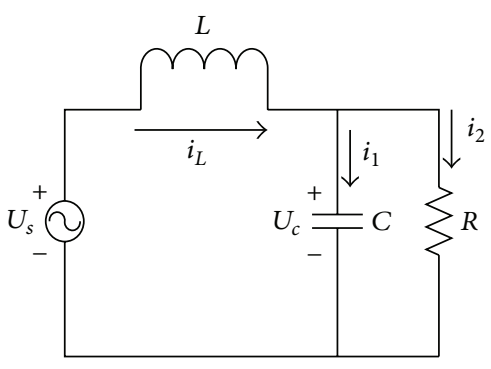

(b)

FIGURE 2: Equivalent circuit diagram of the two switching states of the APF model.

From (1), average state equations of the inverter within one cycle can be obtained as

$$
\begin{aligned}
& \dot{\bar{i}}_{L}(t)=\frac{D}{L}\left(U_{s}+\bar{U}_{c}\right)+\frac{1-D}{L}\left(U_{s}-\bar{U}_{c}\right)=\frac{2 D-1}{L} \bar{U}_{c}+\frac{U_{s}}{L}, \\
& \dot{\bar{U}}_{c}(t)=-\frac{D}{C}\left(\bar{i}_{L}-i_{2}\right)+\frac{1-D}{L}\left(\bar{i}_{L}+i_{2}\right)=\frac{1-2 D}{C} \bar{i}_{L}+\frac{U_{s}}{R C},
\end{aligned}
$$

where, $D \in[0,1]$.

Rewriting (2) yields the following form:

$$
\dot{x}=F x+G x D+E U_{s},
$$

where

$$
\begin{aligned}
& x=\left[\begin{array}{ll}
\bar{i}_{L} & \bar{U}_{c}
\end{array}\right]^{T}, \quad F=\left[\begin{array}{cc}
0 & \frac{-1}{L} \\
\frac{1}{C} & \frac{-1}{R C}
\end{array}\right], \\
& G=\left[\begin{array}{cc}
0 & \frac{2}{L} \\
\frac{-2}{C} & 0
\end{array}\right], \quad E=\left[\begin{array}{ll}
\frac{1}{L} & 0
\end{array}\right]^{T} .
\end{aligned}
$$

In order to simplify the controller design, an approximate linear model of the nonlinear model is derived around the equilibrium point. If $x=x_{0}$ and $D=D_{0}$ satisfying

$$
f\left(x_{0}, D_{0}\right)=G x_{0}+G x_{0} D_{0}+E U_{s}=0,
$$

then $\left(x_{0}, D_{0}\right)$ can be called the equilibrium point of the nonlinear model. Therefore the right side of (3) is expanded into a Taylor series about $\left(x_{0}, D_{0}\right)$, and the high-order terms are neglected as follows:

$$
\dot{x} \approx f(x, D)+\left.\frac{\partial f}{\partial x}\right|_{\substack{x=x_{0} \\ D=D_{0}}}\left(x-x_{0}\right)+\left.\frac{\partial f}{\partial D}\right|_{\substack{x=x_{0} \\ D=D_{0}}}\left(D-D_{0}\right) .
$$

Assuming that $x_{\delta}=x-x_{0}, D_{\delta}=D-D_{0}$, then the following linear APF model can be obtained:

$$
\dot{x}_{\delta}=\left(F+G D_{0}\right) x_{\delta}+\left(G x_{0}\right) D_{\delta} \equiv A_{p} x_{\delta}+B_{p} D_{\delta},
$$

where, $A_{p}=F+G D_{0}, B_{p}=G x_{0}$.
The capacitor voltage and inductance current of the nonlinear APF mode at the point $\left(x_{0}, D_{0}\right)$ can be described as

$$
\begin{gathered}
x_{02}=\frac{U_{s}}{1-2 D_{0}}, \\
x_{01}=\frac{x_{02}}{R\left(1-2 D_{0}\right)},
\end{gathered}
$$

where, $x_{02}$ and $x_{01}$ are the equivalent values of $U_{c}$ and $i_{L}$ respectively. Duty cycle can be expressed as

$$
D_{0}=\frac{1}{2}\left(1-\frac{U_{s}}{x_{02}}\right) .
$$

\section{Adaptive Current Control}

In this section, an adaptive current control for AC side current compensation is derived. A schematic diagram of the model reference adaptive control system is shown in Figure 3.

We can obtain the state equation of the controlled models from (7) as follows:

$$
\dot{x}_{\delta}=A_{p} x_{\delta}+B_{p} D_{\delta},
$$

where $A_{p} \in R^{2 \times 2}, B_{p} \in R^{2 \times 1}, x_{\delta} \in R^{2 \times 1}$, and $D_{\delta} \in R^{1 \times 1}$.

The reference model can be obtained as

$$
\dot{x}_{m}=A_{m} x_{m}+B_{m} r_{p},
$$

where $A_{m} \in R^{2 \times 2}, B_{m} \in R^{2 \times 1}, x_{m} \in R^{2 \times 1}$, and $r_{p} \in R^{1 \times 1}$.

Define tracking error as

$$
e=x_{m}-x_{\delta}
$$

The adaptive controller is proposed as

$$
D_{\delta}=F x_{\delta}+K r_{p} \text {, }
$$

where $F$ and $K$ are feedback and feedforward gain of the closed loop system, respectively.

Substituting (13) into (10) yields

$$
\dot{x}_{\delta}=\left(A_{p}+B_{p} F\right) x_{\delta}+B_{p} K r_{p} .
$$




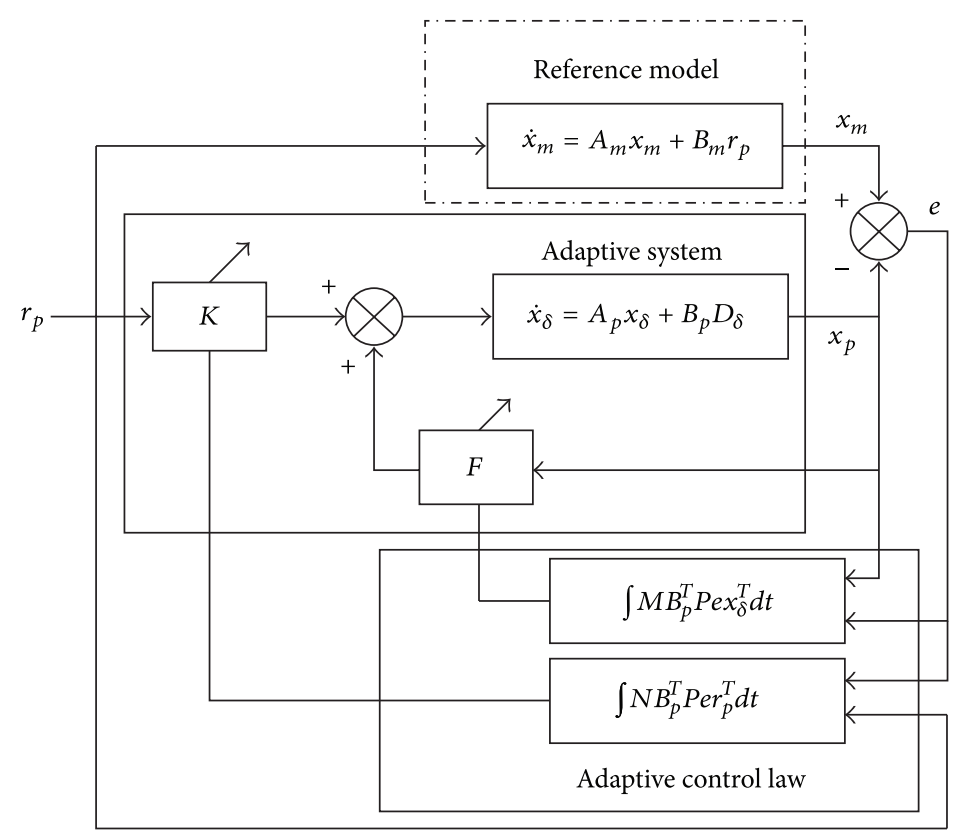

FIGURE 3: MRAC system architecture based on the state variables.

There exist optimal parameters $F^{*}, K^{*}$, such that the following matching condition (15) can be satisfied:

$$
\begin{gathered}
A_{p}+B_{p} F^{*}=A_{m}, \\
B_{p} K^{*}=B_{m} .
\end{gathered}
$$

Substituting (14), (15) into the derivative of tracking error $\dot{e}=$ $\dot{x}_{m}-\dot{x}_{\delta}$ yields

$$
\dot{e}=A_{m} e+B_{p} \widetilde{K}(t)^{T} x_{\delta}+B_{p} \widetilde{F}(t)^{T} r_{p}
$$

where $\widetilde{K}(t)=K(t)-K^{*}, \widetilde{F}(t)=F(t)-F^{*}$.

Define a Lyapunov function

$$
V=\frac{1}{2} e^{T} P e+\frac{1}{2} \operatorname{tr}\left(\widetilde{K} M^{-1} \widetilde{K}^{T}\right)+\frac{1}{2} \operatorname{tr}\left(\widetilde{F} N^{-1} \widetilde{F}^{T}\right),
$$

where $M, N$ are positive-definite matrixes, tr denotes the trace of a square matrix.

Since $A_{m}$ is a Hurwitz stable matrix, there exists a unique positive-definite symmetric matrix $P$ satisfies the following:

$$
A_{m}^{T} P+P A_{m}=-Q
$$

where $Q=Q^{T} \in R^{2 \times 2}$ is positive definite.

Substituting (16) into the derivative of $V(t)$ generates

$$
\begin{aligned}
\dot{V}= & -\frac{1}{2} e^{T} Q e+e^{T} P B_{p} \widetilde{K}^{T} x_{\delta}+e^{T} P B_{p} \widetilde{F}^{T} r \\
& +\operatorname{tr} \widetilde{K} M^{-1} \dot{\widetilde{K}}^{T}+\operatorname{tr} \widetilde{F} M^{-1} \dot{\widetilde{F}}^{T} .
\end{aligned}
$$

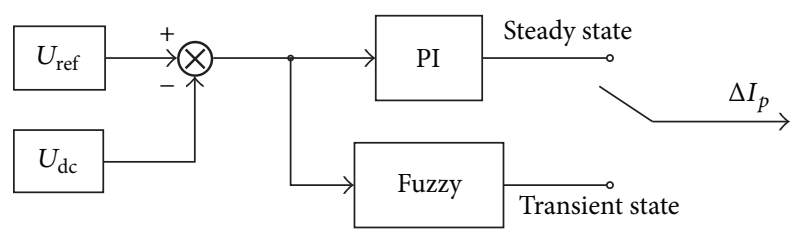

Figure 4: PI-fuzzy compound control structure.

Making use of the properties of matrix trace $x^{T} A x=$ $\operatorname{tr}\left(x x^{T} A\right), \operatorname{tr}(A)=\operatorname{tr}\left(A^{T}\right)$, (19) can be rewritten as

$$
\begin{aligned}
\dot{V}= & -\frac{1}{2} e^{T} Q e+\operatorname{tr}\left(\widetilde{K} B_{p}^{T} P^{T} e x_{\delta}^{T}\right)+\operatorname{tr}\left(\widetilde{F} B_{p}^{T} P^{T} e r^{T}\right) \\
& +\operatorname{tr} \widetilde{K} M^{-1} \dot{\widetilde{K}}^{T}+\operatorname{tr} \widetilde{F} M^{-1} \dot{\widetilde{F}}^{T} .
\end{aligned}
$$

To make $\dot{V} \leq 0$, we choose the adaptive laws as

$$
\begin{gathered}
\dot{K}(t)^{T}=-M B_{p}^{T} P e x_{\delta}^{T}, \\
\dot{F}(t)^{T}=-N B_{p}^{T} e r^{T} .
\end{gathered}
$$

This adaptive laws yield $\dot{V}=-(1 / 2) e^{T} Q e<0$, according to Barbalat lemma, and $e(t)$ will asymptotically converge to zero, $\lim _{t \rightarrow \infty} e(t)=0$.

\section{PI-Fuzzy Compound Voltage Control}

In this section, PI-fuzzy compound controller is designed for the DC side capacitor voltage control. The PI-fuzzy compound controller structure is shown in Figure 4. When system enters the transient state, the fuzzy controller can improve the system dynamic performance. On the contrary, 


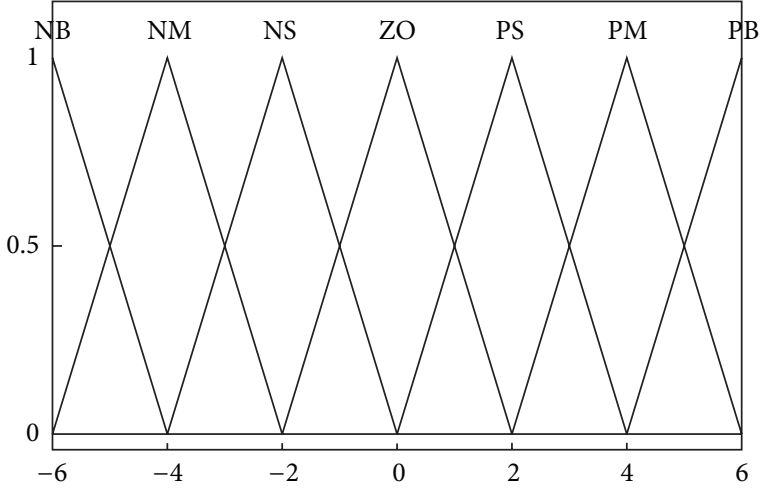

FIgURE 5: Triangular membership function.

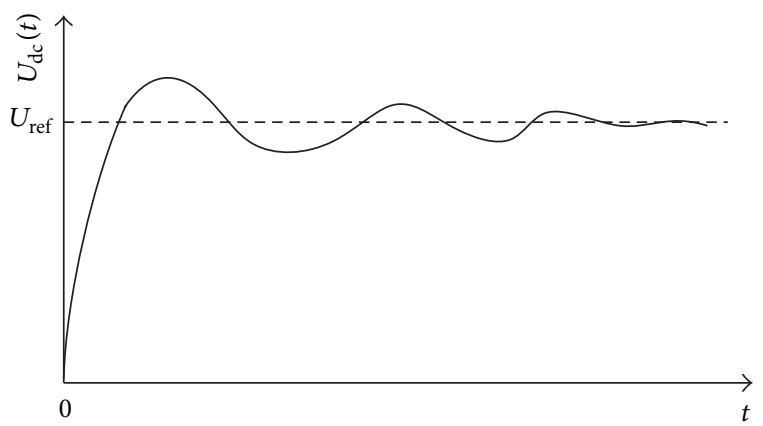

FIgURE 6: The change curve of APF DC capacitor voltage.

if system enters the steady state, PI controller can eliminate steady-state error of the system and improve steady-state performance of the system, where the switching of the controller is defined by the absolute value of the voltage error.

In Figure 4, the parameters of PI controller are set by general tuning method. Using the voltage deviation of each sampling time and the fuzzy rule, fuzzy controller can judge quickly and effectively. The advantage of PI-fuzzy compound controller is that it can automatically switch between PI control and fuzzy control under different operating conditions, so it can take advantages of both approaches, thereby improving system speed and enhancing the robustness under the premise of guaranteeing control precision. The switch between the two controllers depends on the indicators of the actual run-time system. The control program runs continuously and monitors the input and output characteristics of the control system, and coordinates between the two control laws automatically.

Since the two-input fuzzy control is similar to proportional and derivative (PD) control. As an affine nonlinear kinematic system, small range of fluctuation of DC voltage in the regulation is inevitable. In order to reduce the interference brought by the derivative action of the controller, we use one-dimensional fuzzy controller, select the deviation $e_{u}(t)$ between the actual voltage and the reference voltage of the DC side as a fuzzy input variables, and choose $\Delta I_{p}$ as the fuzzy

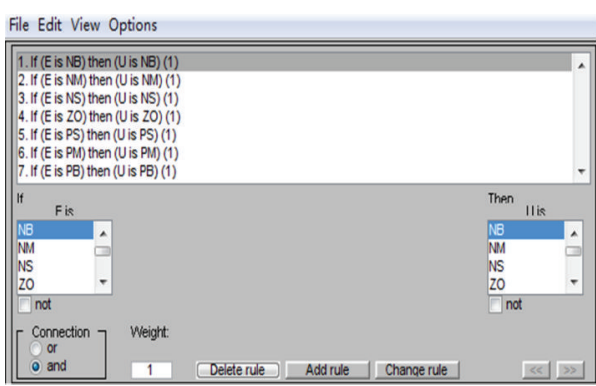

Figure 7: Fuzzy control rule table.

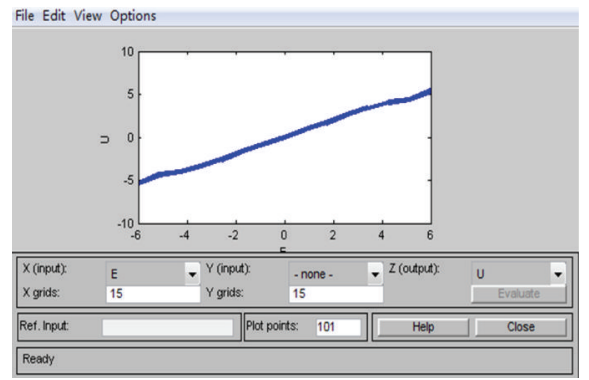

FIGURE 8: Fuzzy controller output curve.

output variables $u$, where $\Delta I_{p}$ is the control amount of the active current that grid injected into the APF main circuit.

Fuzzy input $e_{u}(k)$ is defined as $e_{u}(k)=U_{\text {ref }}-U_{\mathrm{dc}}(k)$, where $U_{\mathrm{dc}}(k)$ is the real value of the DC capacitor voltage for the first time $k, U_{\text {ref }}$ is the reference voltage.

After scale changes, let the universe of input variables $e(t)$ and output variables $u$ of the fuzzy controller are

$$
X=\left\{\begin{array}{lllllllllllll}
-6 & -5 & -4 & -3 & -2 & -1 & 0 & 1 & 2 & 3 & 4 & 5 & 6
\end{array}\right\} .
$$

Select seven of linguistic variables in the universe: NB, $\mathrm{NM}, \mathrm{NS}, \mathrm{ZO}, \mathrm{PS}, \mathrm{PM}$, and PB. The input variables $e_{u}(t)$ and output variables $u$ are selected overlapping symmetrical triangle membership function, as shown in Figure 5.

The fuzzy control rules are the core of the fuzzy control, therefore, how to set up the fuzzy control rules become a crucial issue. The fuzzy control rule is the most natural way to describe the process of human behavior and decision analysis, it establishes the link between the fuzzy input variables and fuzzy output variables, multiform of IF-THEN fuzzy conditional sentences.

Figure 6 is the APF DC voltage reference curve of the change process we can develop fuzzy control rules based on this curve. Fuzzy control rules can be obtained according to the change process; of the curve shown in Figure 6, and the existing experience of DC side capacitor voltage control is shown in Table 1.

The Mamdani type fuzzy inference system containing the fuzzy relationship such as "If $e$ is $A$ then $u$ is $C$ " is adopted. For defuzzification method, the area of the center of gravity (centroid) is selected, then fuzzy controller output value can be obtained, that is, grid controlled amount of active current $\Delta I_{p}$ to be injected into the APF main circuit. 


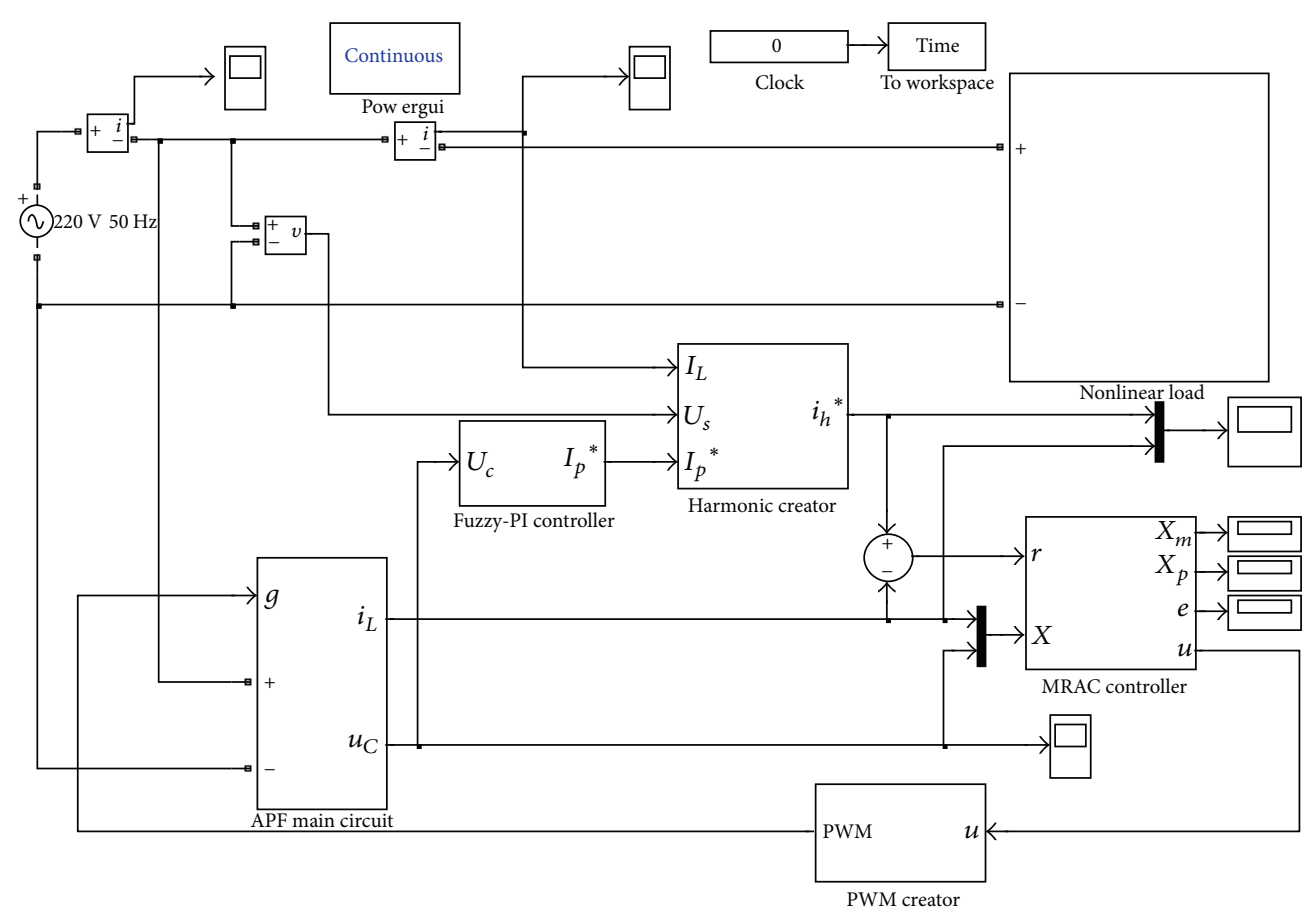

Figure 9: Comprehensive simulation model of active power filter.

TABLE 1: DC side capacitor voltage fuzzy control rules.

\begin{tabular}{lllllll}
\hline$e(t)$ & NB & NM & NS & ZO & PS & PM \\
$u$ & NB & NM & NS & ZO & PS & PB \\
\hline
\end{tabular}

\section{Simulation Study}

Fuzzy controller is completed by using MATLAB fuzzy control editor (FTS), fuzzy control rule table, and fuzzy controller output curve are shown in Figures 7 and 8, respectively.

According to the control schematic block diagrams shown in Figures 3 and 4, the comprehensive model of active power filter based on reference adaptive control and PIfuzzy compound control strategy is established in Figure 9, including nonlinear load module (nonlinear load), harmonic current detection module (harmonic creator), and the main circuit of filtering (APF main circuit). IGBT, within appropriate voltage and current levels, is chosen as switch, the PWM conversion module (PWM creator), adaptive current tracking compensation module (MARC controller), and DC side capacitor voltage fuzzy-PI the compound control module (fuzzy-PI controller), and so on.

In the simulations of adaptive current control based on PI-fuzzy compound control for the active power filter and hysteresis current control, the DC capacitor voltage PI-fuzzy compound control parameters are $K p=0.2$, $K i=0.01$. For comparison purpose, DC capacitor voltage conventional PI control parameters are the same as $K p=0.2$, $K i=0.01$.
TABLE 2: Simulation Parameters.

\begin{tabular}{lc}
\hline Parameters & Value \\
\hline Power & $U_{s}=220 \mathrm{~V}_{\mathrm{rms}} / 50 \mathrm{HZ}$ \\
DC capacitor voltage & $U_{c}=600 \mathrm{~V}$ \\
PWM switching frequency & $f_{s}=20 \mathrm{KHZ}$ \\
Input inductor & $L=6 \mathrm{mH}$ \\
Input capacitor & $C=1000 \mu \mathrm{F}$ \\
Output resistance & $R=1000 \Omega$ \\
Load resistance & $R_{L}=15 \Omega$ \\
Load inductor & $L_{L}=5 \mathrm{mH}$ \\
\hline
\end{tabular}

According to the parameters of Table 2, from (9), (8), and (7), $D_{0}=0.24$,

$$
\begin{gathered}
x_{0}=\left[\begin{array}{ll}
0.11573 & 600
\end{array}\right]^{T}, \\
A_{p}=\left[\begin{array}{cc}
0 & -86.4 \\
518.5 & -0.1
\end{array}\right], \\
B_{p}=\left[\begin{array}{ll}
200000 & -231.5
\end{array}\right]^{T}
\end{gathered}
$$




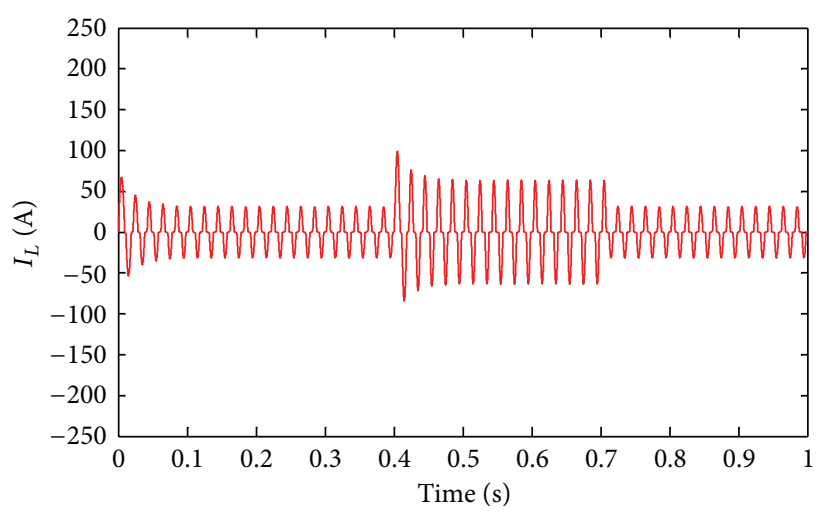

(a)

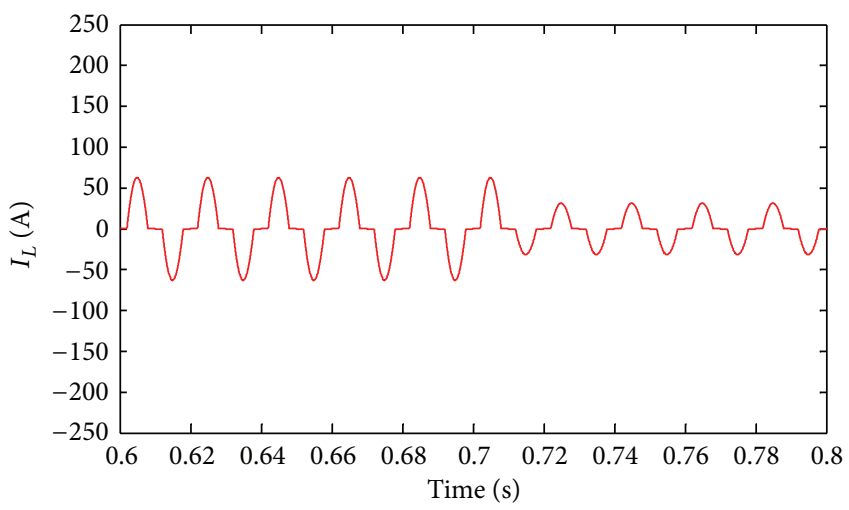

(b)

FIgURE 10: Grid current waveform without APF.

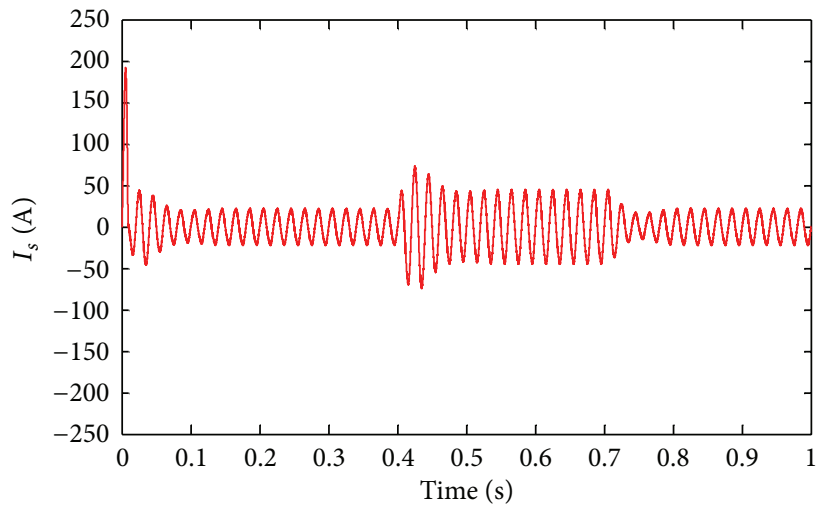

(a)

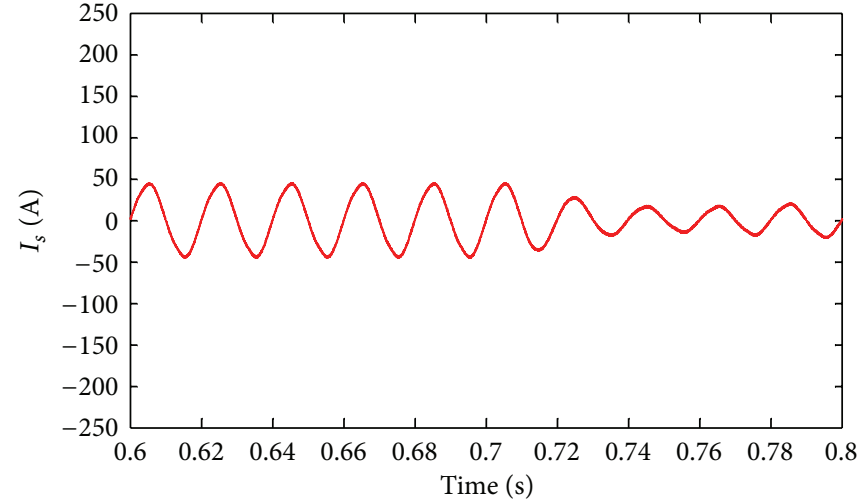

(b)

FIGURE 11: Grid current waveform with adaptive current control based on PI-fuzzy compound control.

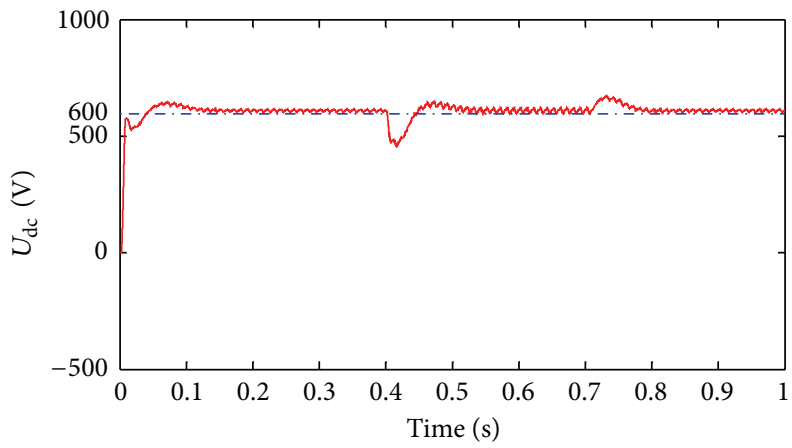

FIGURE 12: Tracking waveform of DC capacitor voltage with PI-fuzzy compound control.

can be obtained, respectively. The positive definite matrixes in (17) and (18) are chosen as

$$
\begin{gathered}
P=\left[\begin{array}{ll}
2.4533 & 0.0833 \\
0.0833 & 2.2274
\end{array}\right], \\
Q=\left[\begin{array}{ll}
1 & 0 \\
0 & 1
\end{array}\right],
\end{gathered}
$$

respectively. The adaptive gains in (21) are

$$
\begin{gathered}
M=0.000125 \text {, } \\
N=\left[\begin{array}{cc}
0.000183 & 0 \\
0 & 0.000262
\end{array}\right] .
\end{gathered}
$$

Regarding the reference model, it is designed as an overdamped system, damping ratio $\zeta=1.4$, rise time 


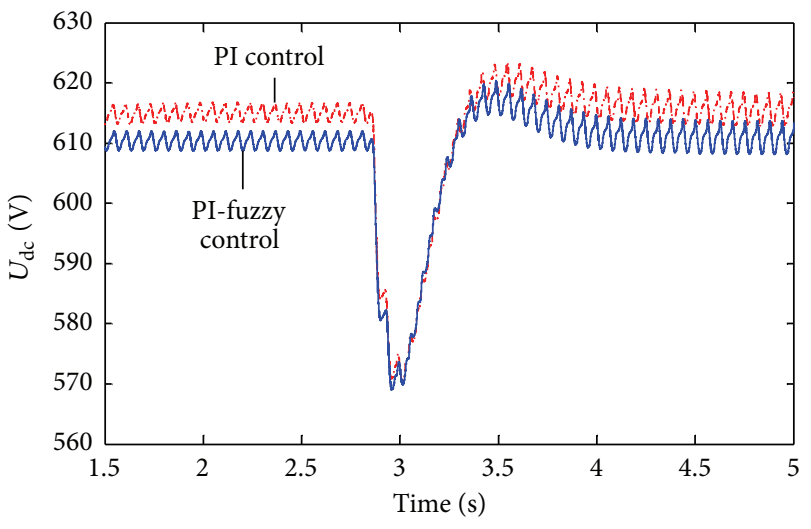

(a)

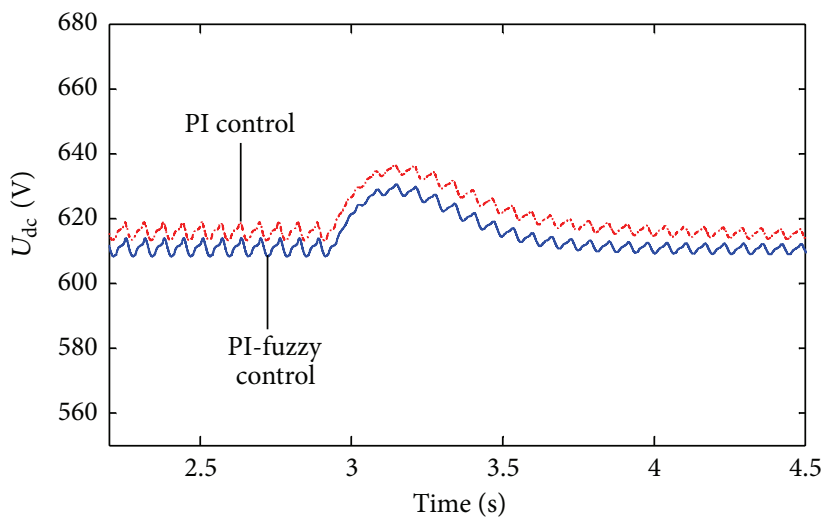

(b)

FIGURE 13: Amplification graph of DC capacitor voltage tracking waveform between conventional PI control and fuzzy-PI compound control with nonlinear load switching.

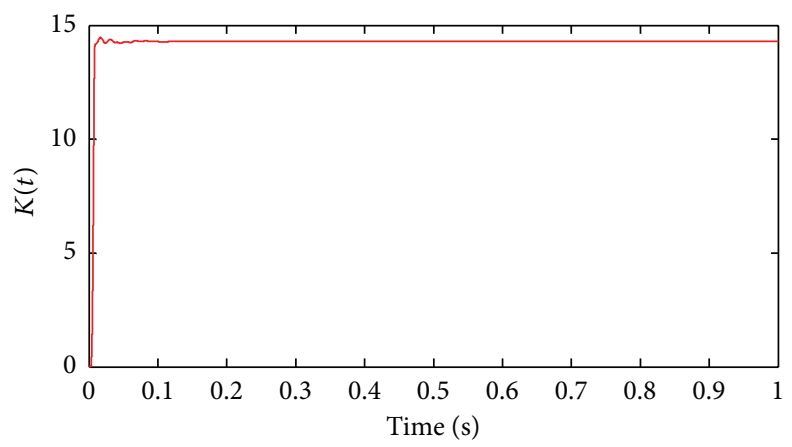

FIGURE 14: Adaptation of MRAC controller's feedforward gain $K$.

$t_{r}=0.169 \mathrm{~s}=\left(1+1.5 \zeta+\zeta^{2}\right) / w_{n}$, then the natural frequency $w_{n}=30 \mathrm{rad} / \mathrm{s}$ can be obtained, adjustment time $t_{s} \approx 3.15 *$ $T_{1} \approx 0.25 \mathrm{~s}$, and the two poles of the reference model can be obtained as -12.6061 and -71.3939 . Then, $A_{m}=\left[\begin{array}{cc}-84-900 \\ 1 & 0\end{array}\right]$ and $B_{m}=\left[\begin{array}{ll}5000 & 40\end{array}\right]^{T}$ can be determined.

During the simulation, the nonlinear load changes twice: first at the time of $0.4 \mathrm{~s}$, parallel nonlinear load is added to the APF system; second at the time of $0.72 \mathrm{~s}$, nonlinear load incorporated to the APF system at $0.4 \mathrm{~s}$ is removed. Figure 10 shows the grid current waveform without APF. It can be seen that due to the effects of nonlinear load, the grid current waveform has severe distortion. Figure 11 is the grid current waveform with adaptive current control based on PI-fuzzy compound control. As can be seen from Figure 11, grid current distortion has been significantly improved with the incorporated APF. Besides, in Figures 10 and 11, (b) is the zoom of (a). Figure 12 is the tracking waveform of DC capacitor voltage with PI-fuzzy compound control while the blue line stands for the default DC capacitor voltage. Figure 13 amplifies the waveforms which compare the DC capacitor voltage tracking between conventional PI control and fuzzy-PI compound control with nonlinear load switching. It can be observed from Figure 13 that DC capacitor voltage with PI-fuzzy compound controller has smaller overshoot, better steady accuracy, robustness, and voltage setting than that with conventional PI control.
It can be seen from Figures 14 and 15, the feedforward gain $K$ and feedback gain $F$ converge to the stable values after short time. These two adaptive parameters are updated online to make the current track reference model as close as possible.

Figure 16 shows that nonlinear load leads grid current containing a large number of harmonics, where THD = $45.80 \%$. Figure 17 plots the harmonic content with hysteresis control based on PI-fuzzy control, where THD $=5.79 \%$. Figure 18 draws the total harmonic content with adaptive current control based on PI-fuzzy control, where THD = $3.84 \%$. Figures 16,17 , and 18 are all measured in $60 \mathrm{~Hz}$, and the fundamental currents are the same. It is shown that adaptive current control with PI-fuzzy compound control is effective in harmonic suppression of APF.

It can be concluded that the current tracking and THD performance can be improved by using the proposed adaptive current control with PI-fuzzy control. Thus the control performance and robustness to nonlinear load can be improved.

\section{Conclusion}

In this paper the approximate mathematical model of the active power filter is established; model reference adaptive current tracking control method for AC side current is developed; PI-fuzzy compound control is designed for the DC capacitor voltage regulation. Simulation studies prove 


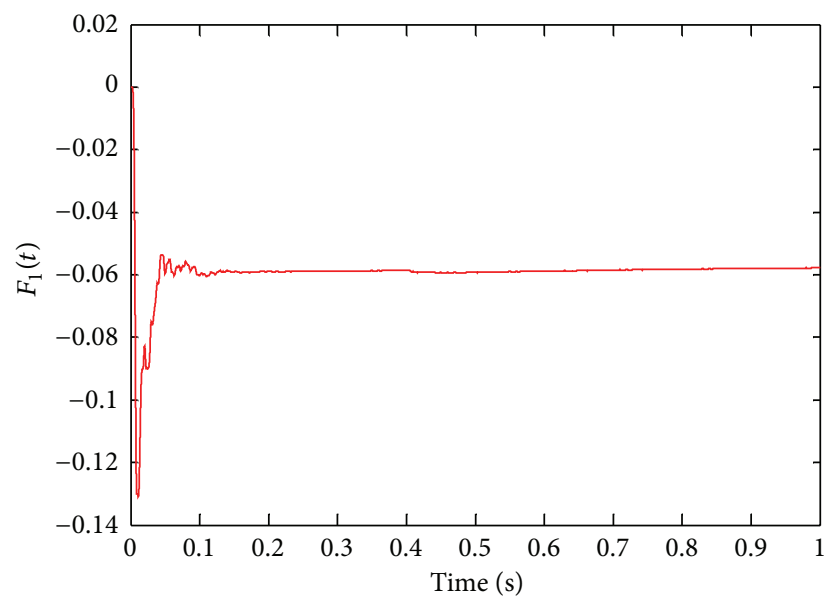

(a)

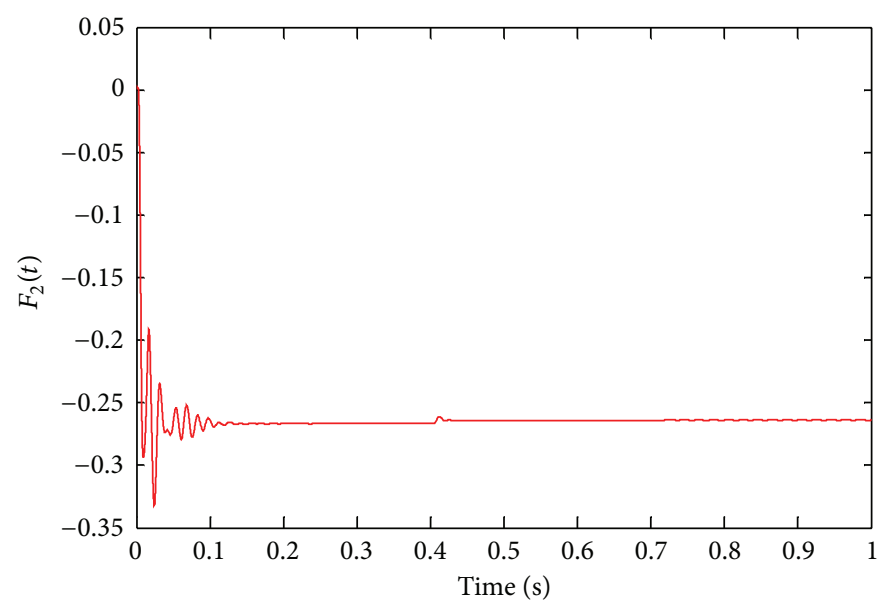

(b)

FIGURE 15: Adaptation of MRAC controller's feedback gain $F$.

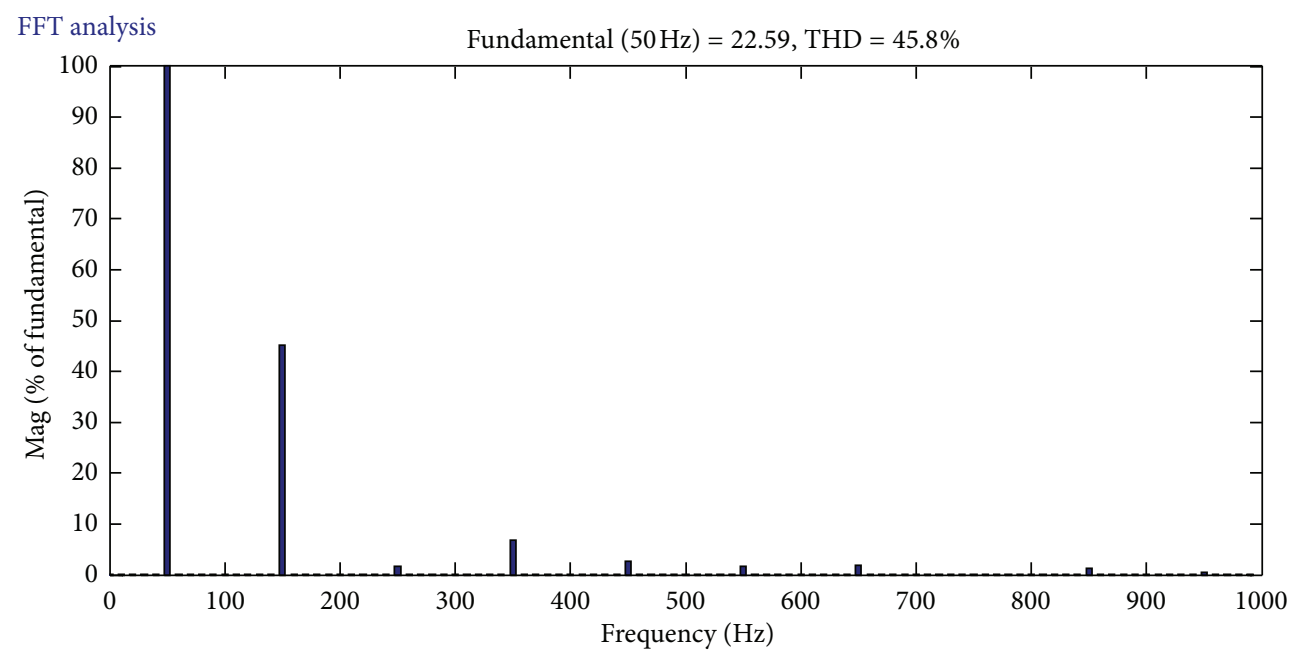

FIGURE 16: Grid current spectrogram without active power filter.

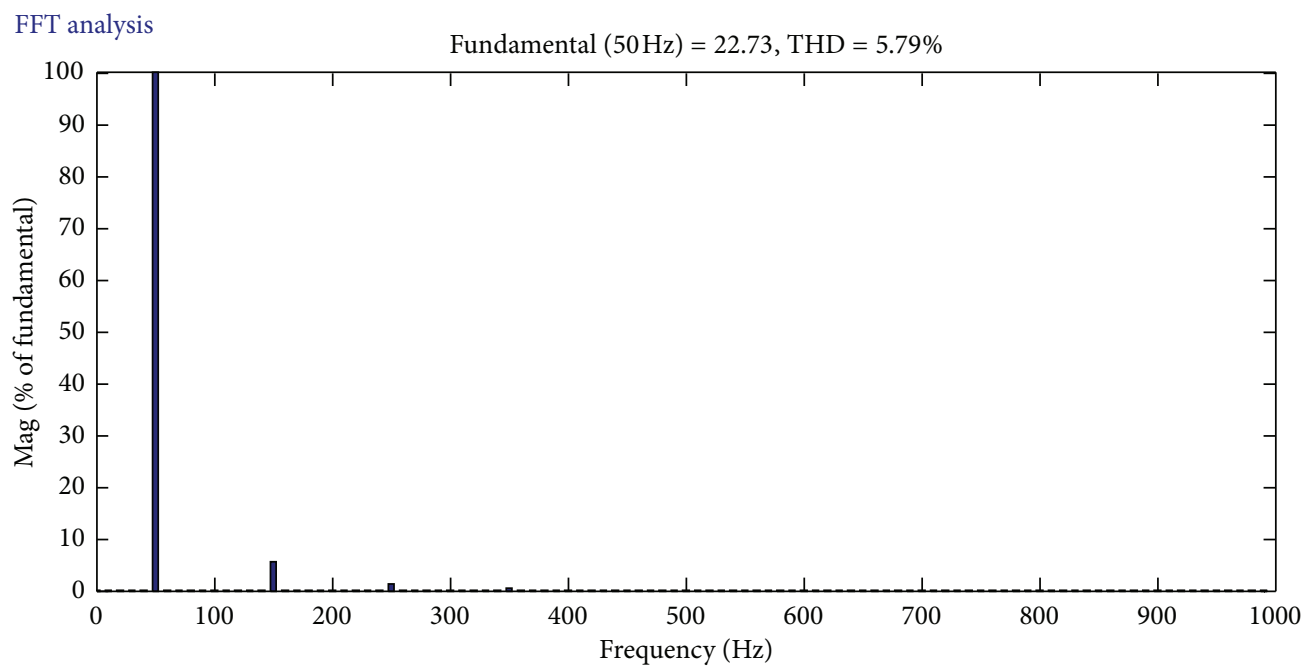

FIGURE 17: Grid current spectrogram with hysteresis control of active power filter based on PI-fuzzy compound control. 


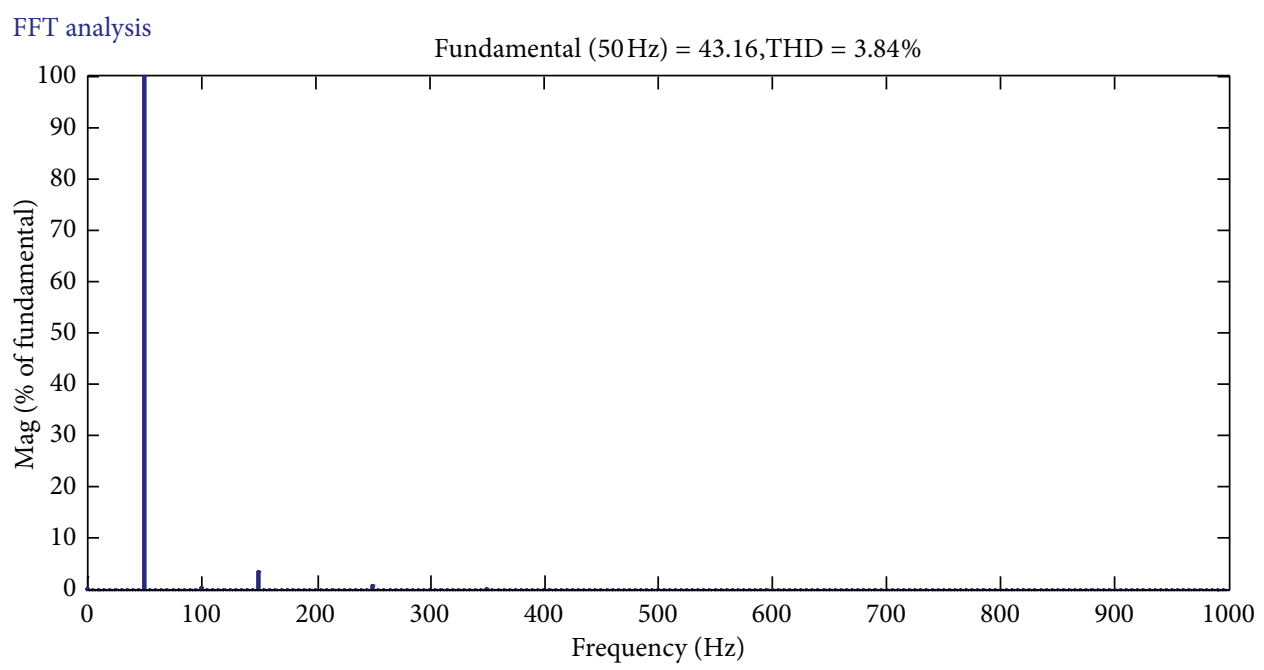

FIGURE 18: Grid current spectrogram with adaptive current control based on PI-fuzzy compound control.

that adaptive current control method based on PI-fuzzy compound control not only can regulate the DC capacitor voltage but also track the AC current command signals, eliminate the power harmonics, and improve the power quality and system robustness.

\section{Acknowledgments}

The authors thank the anonymous reviewers for useful comments that improved the quality of the paper. This work is partially supported by National Science Foundation of China under Grant no. 61074056; the Scientific Research Foundation of High-Level Innovation and Entrepreneurship Plan of Jiangsu Province; the Fundamental Research Funds for the Central Universities under Grant no. 2012B06714.

\section{References}

[1] S. Rahmani, K. Al-Haddad, and H. Y. Kanaan, "A comparative study of shunt hybrid and shunt active power filters for singlephase applications: simulation and experimental validation," Mathematics and Computers in Simulation, vol. 71, no. 4-6, pp. 345-359, 2006.

[2] S. Rahmani, N. Mendalek, and K. Al-Haddad, "Experimental design of a nonlinear control technique for three-phase shunt active power filter," IEEE Transactions on Industrial Electronics, vol. 57, no. 10, pp. 3364-3375, 2010.

[3] S. Wang and A. Luo, "Study of dead-time effect and its compensation strategies," High Voltage Engineering, vol. 35, no. 5, pp. 1170-1176, 2009.

[4] H. Vahedi, A. Sheikholeslami, M. Bina, and M. Vahedi, "Review and simulation of fixed and adaptive hysteresis current control considering switching losses and high-frequency harmonics," Advances in Power Electronics, vol. 2011, Article ID 397872, 6 pages, 2011.

[5] B. Singh, K. Al-Haddad, and A. Chandra, "A review of active filters for power quality improvement," IEEE Transactions on Industrial Electronics, vol. 46, no. 5, pp. 960-971, 1999.
[6] B. Singh, K. Al-Haddad, and A. Chandra, "A new control approach to three-phase active filter for harmonics and reactive power compensation," IEEE Transactions on Power Systems, vol. 13, no. 1, pp. 133-138, 1998.

[7] H. Komucugil and O. Kukrer, "A new control strategy for singlephase shunt active power filters using a Lyapunov function," IEEE Transactions on Industrial Electronics, vol. 53, no. 1, pp. 305-312, 2006.

[8] P. Kumar and A. Mahajan, "Soft computing techniques for the control of an active power filter," IEEE Transactions on Power Delivery, vol. 24, no. 1, pp. 452-461, 2009.

[9] G. W. Chang and T.-C. Shee, "A novel reference compensation current strategy for shunt active power filter control," IEEE Transactions on Power Delivery, vol. 19, no. 4, pp. 1751-1758, 2004.

[10] K. K. Shyu, M. J. Yang, Y. M. Chen, and Y. F. Lin, "Model reference adaptive control design for a shunt active-power-filter system," IEEE Transactions on Industrial Electronics, vol. 55, no. 1, pp. 97-106, 2008.

[11] J. Matas, L. Garcia de Vicuna, J. Miret, J. M. Guerrero, and M. Castilla, "Feedback linearization of a single-phase active power filter via sliding mode control," IEEE Transactions on Power Electronics, vol. 23, no. 1, pp. 116-125, 2008.

[12] C. C. Hua, C. H. Li, and C. S. Lee, "Control analysis of an active power filter using Lyapunov candidate," IET Power Electronics, vol. 2, no. 4, pp. 325-334, 2009.

[13] M. I. M. Montero, E. R. Cadaval, and F. B. González, "Comparison of control strategies for shunt active power filters in three-phase four-wire systems," IEEE Transactions on Power Electronics, vol. 22, no. 1, pp. 229-236, 2007.

[14] A. A. Valdez, G. Escobar, and R. Ortega, "An adaptive controller for the shunt active filter considering a dynamic load and the line impedance," IEEE Transactions on Control Systems Technology, vol. 17, no. 2, pp. 458-464, 2009.

[15] L. Marconi, F. Ronchi, and A. Tilli, "Robust nonlinear control of shunt active filters for harmonic current compensation," Automatica, vol. 43, no. 2, pp. 252-263, 2007.

[16] V. B. Sriram, S. Gupta, and A. Patra, "Indirect current control of a single-phase voltage-sourced boost-type bridge converter 
operated in the rectifier mode," IEEE Transactions on Power Electronics, vol. 18, no. 5, pp. 1130-1137, 2003.

[17] H. L. Jou, J. C. Wu, Y. J. Chang, and Y. T. Feng, "A novel active power filter for harmonic suppression," IEEE Transactions on Power Delivery, vol. 20, no. 2, pp. 1507-1513, 2005.

[18] Z. H. Shuai, A. Luo, W. Zhu, R. Fan, and K. Zhou, "Study on a novel hybrid active power filter applied to a high-voltage grid," IEEE Transactions on Power Delivery, vol. 24, no. 4, pp. 23442352, 2009.

[19] H. Carranza, A. Medina, and G. W. Chang, "Real-time shunt active power filter compensation," IEEE Transactions on Power Delivery, vol. 23, no. 4, pp. 2623-2625, 2008.

[20] G. K. Singh, A. K. Singh, and R. Mitra, "A simple fuzzy logic based robust active power filter for harmonics minimization under random load variation," Electric Power Systems Research, vol. 77, no. 8, pp. 1101-1111, 2007.

[21] C. N. Bhende, S. Mishra, and S. K. Jain, "TS-fuzzy-controlled active power filter for load compensation," IEEE Transactions on Power Delivery, vol. 21, no. 3, pp. 1459-1465, 2006. 


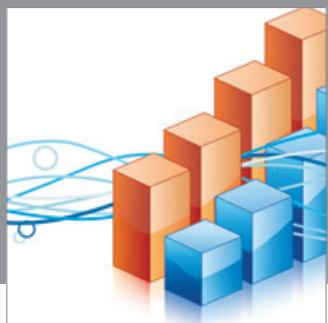

Advances in

Operations Research

mansans

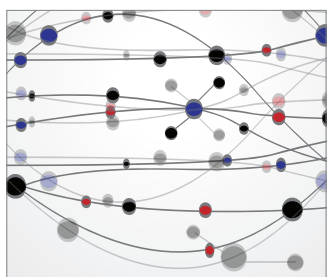

The Scientific World Journal
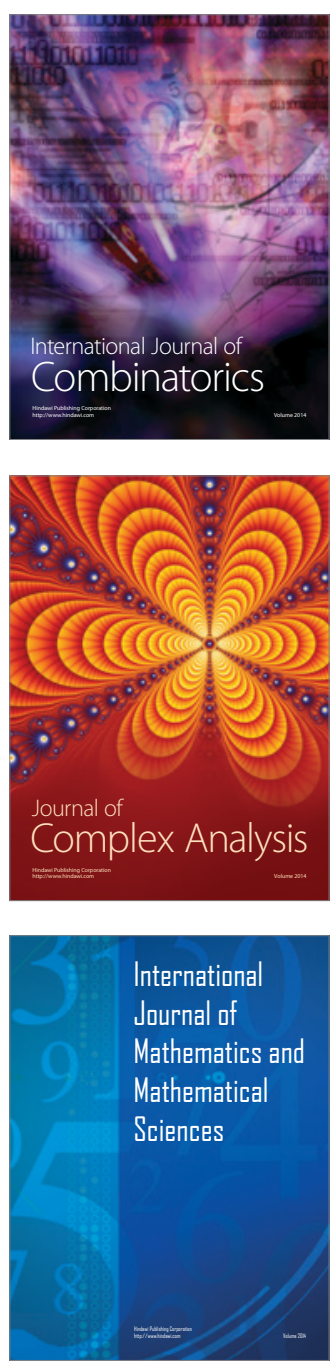
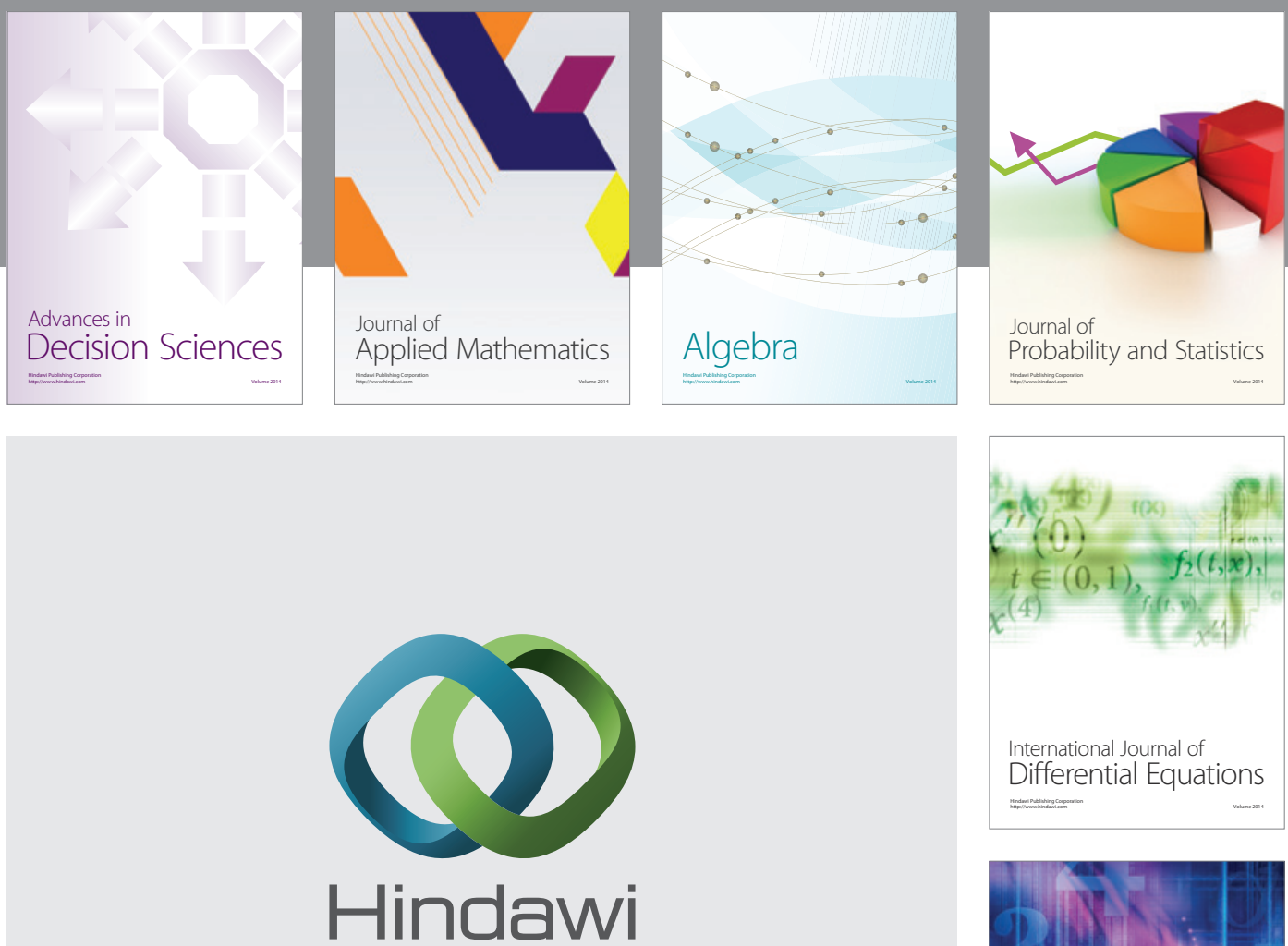

Submit your manuscripts at http://www.hindawi.com
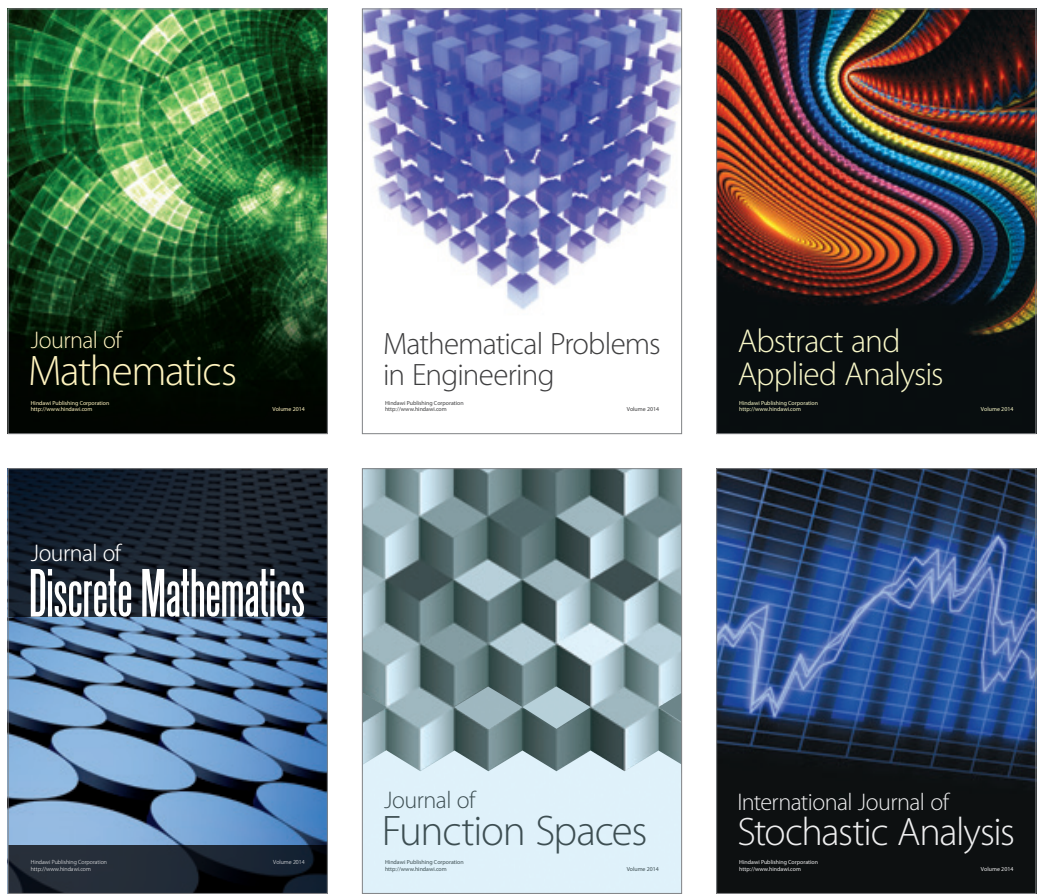

Journal of

Function Spaces

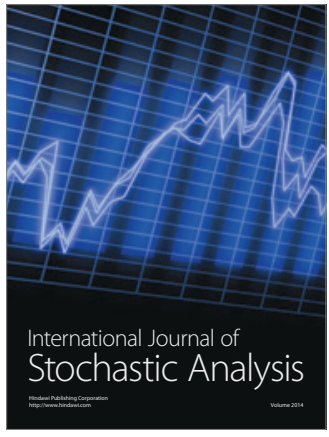

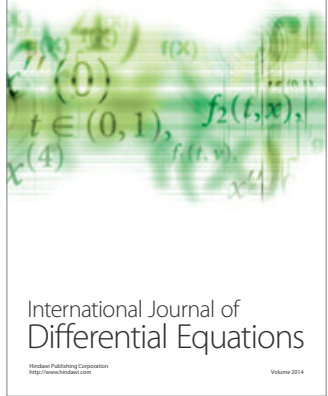
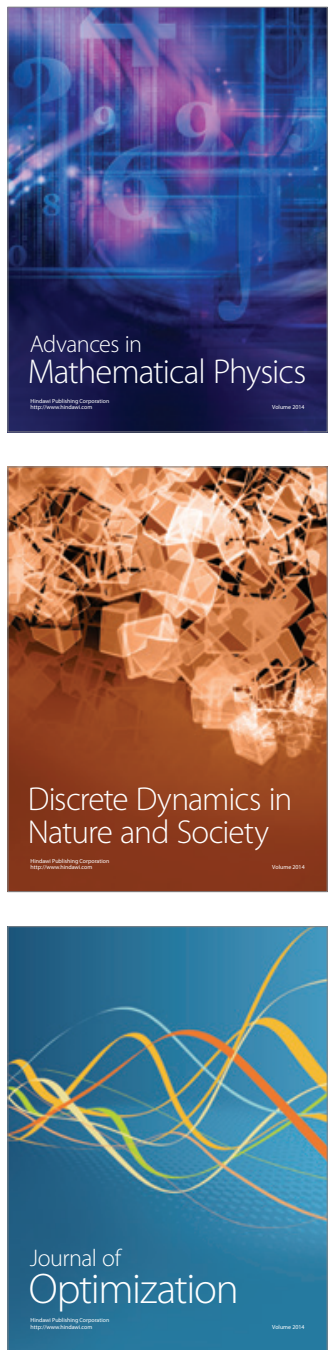